\title{
Mercado de trabajo, género y especialización oleícola: Mallorca a mediados del siglo XVII
}

\author{
Gabriel Jover-Avellà y Joana Maria Pujadas-Mora
}

\begin{abstract}
PALABRAS CLAVE: mercado de trabajo agrario, género, mano de obra jornalera, brecha salarial.
\end{abstract}

CÓDIGOS JEL: J43, J16, J82, J31.

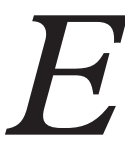

n los últimos años se ha desarrollado un amplio debate historiográfico sobre la participación de las mujeres en los mercados de trabajo rurales y su impacto sobre la brecha salarial de género antes de 1800. La hipótesis subyacente que se plantea es que el aumento de la participación de las mujeres en el mercado de trabajo debería conducir a una reducción de la brecha salarial de género y una mejora de sus condiciones de vida. Sin embargo, los resultados hasta el momento no son concluyentes en este sentido. Este artículo se propone abordar algunas de estas cuestiones a partir de un estudio de caso sobre la isla de Mallorca durante el siglo XVII. En este trabajo se presentarán evidencias de una intensa participación femenina en el mercado de trabajo, superior a la de otras regiones mediterráneas y atlánticas. Además, se mostrará que la estacionalidad de la demanda de trabajo seguía pautas diferentes a las señaladas en las regiones atlánticas, lo que provocó más colusiones que complementariedades. Por último, se explicará cómo la mayor ocupación femenina no suponía necesariamente una reducción significativa de la brecha salarial de género. 


\title{
Labour market, gender and olive groves specialization: Mallorca at $\mathrm{mid} 17^{\text {th }}$ century
}

\author{
KEYWORDS: agricultural labour markets, gender, daily-labourers, \\ wage gap.
}

JEL CODES: J43, J16, J82, J31.

ecently, an intense historiographical debate has developed concerning female
participation in rural labour markets and its impact on the gender wage gap
before 1800. The underlying hypothesis is that increased participation of women in the labour market should lead to a reduction in the wage gap and a parallel improvement in their life conditions. However, research results to date are inconclusive. This article aims to address some of these issues, using the island of Mallorca during the seventeenth century as a case study. Female participation in the labour market was more intense there than in other Mediterranean and Atlantic regions. In addition, the seasonality of labour demand on the island provoked more instances of collusion than complementarity with regard to agrarian tasks, in contrast with what happened in Atlantic regions. Finally, we also explain why higher rates of female occupation did not necessarily imply a significant reduction of the gender wage gap.

Recepción: 2018-11-13 - Revisión: 2019-06-18 • Aceptación: 2019-06-21

Gabriel Jover-Avellà [orcid.org/0000-0002-6430-2329] es profesor titular de Historia e Instituciones Económicas en la Universidad de Girona. Dirección para correspondencia: Departamento de Economía, Facultad de Ciencias Económicas y Empresariales, Universidad de Girona, cl de la Universitat de Girona, 10, Campus Montilivi, 17003 Girona (España).C.e.gabriel.jover@udg.edu

Joana Maria Pujades-Mora [orcid.org/0000-0002-4975-639X] es investigadora principal del área de demografía histórica del Centre d'Estudis Demográfics de la Universitat Autònoma de Barcelona, y profesora asociada del departamento de Historia Económica, Instituciones, Política y Economía Mundial de la Universidad de Barcelona. Dirección para correspondencia: Centre d'Estudis Demogràfics, carrer de Ca n'Altayó, s/n, Edifici E2, Campus Universitat Autònoma de Barcelona, 08193 Bellaterra (España). C. e.: jpujades@ced.uab.es 


\section{LAS MUJERES EN LOS MERCADOS DE TRABAJO AGRARIOS PREINDUSTRIALES}

En los últimos años se ha desarrollado un amplio debate historiográfico sobre la participación de las mujeres en los mercados de trabajo rurales y su impacto sobre la brecha salarial de género antes de $1800^{1}$. La hipótesis subyacente que se plantea es que el aumento de la participación de las mujeres en el mercado de trabajo debería conducir a una reducción de la brecha salarial de género y una mejora de sus condiciones de vida. Sin embargo, los resultados hasta el momento no son concluyentes en este sentido (Moor \& Zanden, 2010; Zanden, 2011; Dennison \& Ogilvie, 2014; Humphries \& Weisdorf, 2015, 2016; De Pleijt \& Zanden, 2018). A su vez, tampoco se ha llegado a un consenso sobre la naturaleza y relevancia del salario en el ingreso de las familias campesinas (Hatcher, 2018). De hecho, las controversias sobre estos temas, en parte, proceden de la opacidad de las fuentes oficiales (censos y padrones) por lo que respecta al trabajo femenino dentro y fuera del hogar (Humphries \& Sarasúa, 2012), particularmente en el sector agrario (Schmidt \& Nederveen Meerkerk, 2012: 88; Ortega, 2015: 13-25). Además, existen pocos estudios sobre los países mediterráneos y en general de los siglos XVI y XVII sobre estos temas (Rey, 2015; Whittle \& Hailwood, 2018).

Los resultados más robustos sobre la participación de las mujeres en los mercados de trabajo agrario sugieren que su participación era menor que en los sectores manufacturero y servicios. En el sector agrario la segmentación del trabajo por sexos era mayor, y la ocupación femenina e infantil se concentraba en las operaciones menos cualificadas (Sharpe, 1995; Verdon, 2002; Ogilvie, 2003; Schmidt \& Nederveen Meerkerk, 2012; Muñoz Abeledo, 2012; Hernández, 2013; Garrido, 2016; Sarasúa, 2019). Además, la demanda de trabajo asalariado agrícola presentaba una elevada estacionalidad que limitaba las posibilidades de convertirlo en una fuente de ingresos continuada para la mayoría de la población (Hindle, 2013; Gary, 2019). En verdad, el desarrollo del capitalismo agrario, con una mayor especialización productiva, contribuyó a acentuar la estacionalidad de la demanda de trabajo, agravando así la elevada subocupación estacional (Tribe, 1981: 90-94; Snell, 1987). Asimismo, los cambios técnicos redujeron la proporción de mano de obra femenina e infantil contratada, con menor merma en las zonas donde dominaban las actividades pecuarias (Allen, 2004: 77-79; Burnette, 2018).

1. El debate se centra en la participación de las mujeres en el mercado de trabajo remunerado, utilizando el salario como indicador. Por tanto, no se computan los ingresos del trabajo de las mujeres en la comercialización de productos, ni el conjunto de trabajos domésticos y reproductivos no remunerados (Borderías, PÉrez-Fuentes \& SARAsúa, 2014; CABANa, 2018; MARCo, 2018). 
Los estudios sobre los salarios han mostrado que la remuneración de las mujeres era netamente inferior a la de los hombres para una misma labor. Esta brecha salarial de género persistió durante toda la Baja Edad Media y Moderna, aunque se redujo moderadamente en las etapas de intensa demanda de trabajo (Humphries \& Weisdorf, 2015, 2016; Gary, 2017). Una menor tasa de actividad e inferiores salarios de la mano de obra femenina son partes de un binomio controvertido. Por una parte, una corriente importante de historiadoras ha señalado la imposición de las relaciones económicas y patriarcales como la causa de esas desigualdades (Sarasúa \& Gálvez Muñoz, 2003; Humphries, 2013; Borderías \& Gálvez Muñoz, 2014); mientras que otras han argumentado que la explicación debe buscarse en las diferentes productividades marginales de hombres y mujeres (Burnette, 2008; Humphries, 2009).

Por tanto, aún queda trecho por recorrer antes de poder concretar de forma fehaciente cuál fue la evolución de la participación de hombres y mujeres en los mercados de trabajo agrario antes de 1800, y disponer de series homogéneas y comparables de salarios para determinar de forma más precisa la evolución de la brecha salarial de género y su explicación. Este artículo se propone abordar algunas de estas cuestiones a partir de un estudio de caso sobre la isla de Mallorca durante el siglo XVII.

En la isla de Mallorca a lo largo de los siglos XV y XVI se produjeron intensos conflictos sociales por la posesión de la tierra que cristalizaron en una derrota campesina y una fuerte acumulación de tierras en manos de una nueva aristocracia terrateniente (Tello et al., 2018). Uno de los rasgos originales del desarrollo agrario de la isla fue la intensa transformación de los mercados de trabajo en el siglo Xvi con la desaparición de la esclavitud y la creación de un amplio mercado de trabajo asalariado (Jover et al., 2019). El avance de este capitalismo agrario fue más intenso en el sector oleícola como consecuencia de que los predios destinaban sus producciones de aceite a los mercados atlánticos (Bibiloni, 1995). Estas grandes explotaciones eran gestionadas directamente por los terratenientes o arrendadas a corto plazo a mercaderes y labradores, que contrataban mano de obra asalariada. La demanda de trabajo se componía de un contingente de mozos rurales, que constituyeron la mano de obra permanente, y otro de mano de obra a jornal. Desde el siglo XVI este mercado de trabajo adquirió algunos rasgos peculiares: una monetización creciente de los salarios, la ausencia de restricciones a la movilidad de la fuerza de trabajo y la creciente participación de mano de obra femenina e infantil (Montaner \& Le Senne, 1981; Jover \& Pons, 2012; Grau \& Tello, 1985; Escartín, 2001).

En este estudio se presentarán evidencias de una intensa participación femenina en el mercado de trabajo, superior a la de otras regiones mediterráneas y atlánticas. Además, se mostrará que la estacionalidad de la demanda de trabajo seguía pautas diferen- 
tes a las señaladas en las regiones atlánticas, lo que provocó más colusiones que complementariedades en la demanda. Por último, se explicará cómo una mayor ocupación femenina no suponía necesariamente una reducción significativa de la brecha salarial de género.

Para revelar esas especificidades de los mercados de trabajo isleños, se ha optado por un enfoque microeconómico. Esta es una de las opciones analíticas más factible por la naturaleza de las fuentes disponibles para el estudio de este tema en el siglo XVII, básicamente libros de cuentas de las haciendas. El análisis de una hacienda agraria, en nuestro caso la de la casa Burgués-Safortesa, puede ser especialmente revelador, pues era la unidad de explotación (la empresa) donde los procesos globales eran interpretados y traducidos en acciones por los actores, impulsando también desde abajo macroefectos en el conjunto de la economía (Ploeg, 2016: 43). De esta manera, las modalidades de contratación y remuneración del trabajo en una hacienda agraria pueden interpretarse como un destilado específico del funcionamiento de los mercados de trabajo agrícolas a escala global.

El artículo se ha organizado de la siguiente manera: en el segundo apartado se presentan y discuten las fuentes utilizadas; en el apartado tercero se analizan las modalidades de contratación y composición estacional de la demanda por labores y género, los mercados de reclutamiento de la mano de obra y la remuneración de la mano de obra en esa hacienda; en el cuarto se proyectan los resultados de este caso de estudio en el contexto general español y europeo; y el estudio se cierra con unas conclusiones.

\section{LAS FUENTES: LOS LIBROS DE CUENTAS DE EXPLOTACIÓN DEL PATRIMONIO BURGUÉS-SAFORTESA, 1645-1694}

En 1652 el segundo conde de Formiguera, Ramon Burgués-Safortesa y Fuster (16271694) había heredado un extenso patrimonio agrario compuesto por diversos predios olivareros, los dominios feudales en la parroquia de Santa Margalida (en el centro cerealista de la isla) y otros bienes inmuebles (casas y predios cerealistas en el término de Palma) y numerosas rentas fijas (Montaner \& Le Senne, 1977). En su testamento de 1689 el conde instituyó como heredera usufructuaria de todos sus bienes a su tercera esposa, Joana Nuniç de Sant Joan (1663-1729) ${ }^{2}$. Tras su defunción, los bienes vinculados debían pasar a sus descendientes, y los bienes patrimoniales no vinculados fueron donados al Capítulo de la Catedral. En el archivo de la catedral de Palma se han conservado una parte

2. Archivo del Reino de Mallorca (ARM), Protocolos notariales (PN), T-1004, ff. 299-315v. 
importante de los libros de administración de los predios olivareros de S'Estorell, Galatzó, Son Pont y Son Togores, y otros bienes donados al Capítulo ${ }^{3}$.

El predio S'Estorell constituirá el laboratorio de este estudio. De este predio se han conservado dos manuales de cuentas de $1658-1671^{4}$ y $1671-1680^{5}$, y los pliegos de las campañas de recogida de la aceituna de los años 1658-1659 a 1679-16806. Los libros de cuentas registraban los gastos salariales y el número de jornales de las labores de mantenimiento de todos los cultivos, y el monto total de los pagos realizados a cada persona contratada, además de la compra de inputs y de bienes de reposición. Las libretas de las campañas de recolección de la aceituna anotaban el número de jornales y los salarios de la recolección de las aceitunas y los de fabricación del aceite. Desgraciadamente no se han conservado los pliegos de la recogida de aceitunas de los años 1673-1674, 1675-1676 y 1676-1677, y tampoco la información completa de los mozos a partir de 1675-1676. Para este estudio, se ha prescindido de los años con lagunas documentales.

En el análisis de todas las categorías laborales se utilizará la información de los años comprendidos entre 1658-1659 a 1672-1673, y para la mano de obra a jornal los años de $1658-1659$ a $1672-1673,1674-1675$ y de $1677-1678$ a 1679-1680. Para completar la información sobre la remuneración y contratación de la mano de obra de este predio, se han utilizado los libros de cuentas, aunque incompletos, de los otros predios de la hacienda ${ }^{7}$ y los libros de cuentas de explotación de algunos predios olivareros cercanos a los de la hacienda Safortesa ${ }^{8}$.

Para el tratamiento de estas fuentes, cabe tener en cuenta que las semanas de trabajo eran de seis días efectivos, y cuando los contratos se hacían por meses, estos se contaban de cuatro semanas efectivas de seis días laborables también: per tota semana que son estats 6 dies («para toda semana que son 6 días»). Cuando se producía una interrupción de

3. Archivo Capitular de Mallorca (ACM), Libros de administración y albaranes del patrimonio, 14158, 14162, 14163 (1637-1687).

4. El libro de cuentas 14204 contiene los registros de gasto de $1645-1647,1652-1657$, aunque incompletos (ACM).

5. En este segundo manual de cuentas no se registró el contrato de los mozos a partir de 1675. Las notas insertas en este manual remiten a un tercer manual que no se ha conservado (ACM, 14193).

6. ACM, 16922, 16923.

7. Los libros de cuentas de 1631-1640 (ACM, 14196, 14197, 14200), y de 1662-1665 y $1677-$ 1679 (ACM, 16923).

8. Es Verger cuentas de 1650-1663 y 1681-1711 (ARM, AH, C-4267, 4269 y 4270), ambos situados en la parroquia de Puigpunyent, y del predio Son Fuster entre 1666-1673 (ARM, PN, S1728, ff. 308-414) propiedad de otra línea de la casa Pax-Fuster y situado entre Selva e Inca, próximo a S'Estorell. 
la jornada de trabajo, por mal tiempo o abandono de la labor, el administrador descontaba el día de trabajo o bien anotaba la proporción del jornal realizada, por ejemplo mig jornal («medio jornal») ${ }^{9}$. Parte de las labores eran contratadas a destajo. Para estimar el número de los jornales de esas labores, se ha dividido el monto del destajo por el salario pagado por esa misma labor dada a jornal en el mismo año.

Aunque los libros de cuentas registraban explícitamente la mayor parte del trabajo femenino, muestran una mayor opacidad respecto del trabajo infantil. Los registros que atribuían explícitamente jornales de trabajo a chicos o niños son muy pocos, y se identificaban con los apelativos de al·lots y bergants, y al·lotes en el caso de las niñas. Para hacer una estimación del número de jornales infantiles más realista, se ha procedido de la siguiente manera: por una parte, se han contabilizado aquellos jornales en los que explícitamente se decía que eran realizados por niños o niñas en los libros de cuentas de explotación. Por otra parte, en los pliegos de las cuadrillas de cogedoras el administrador diferenciaba mediante una remuneración inferior el salario de los niños o niñas del de los adultos o adultas. De esta manera, esos salarios inferiores se han atribuido a la mano de obra infantil, como se había procedido en anteriores trabajos (Jover, 2013a, 2015).

\section{MODALIDADES DE CONTRATACIÓNY REMUNERACIÓN DE LA MANO DE OBRA EN LA HACIENDA BURGUÉS-SAFORTEZA, 1658-1680}

El predio s'Estorell estaba situado en la parroquia de Binissalem, al pie de la sierra de Tramuntana. S'Estorell era el predio más extenso del término, y uno de los 10 más rentables de la isla, con una valoración de 52.000 libras según el catastro de $1685^{10}$. El predio tenía una extensión de algo más de 520 hectáreas y ocupaba prácticamente todo el valle de Almadrà hasta las primeras cimas de la sierra en las villas de Alaró y Selva ${ }^{11}$. Por el sudoeste y por el noroeste lindaba con otras grandes explotaciones olivareras que ocupaban las vertientes de la sierra. Los llanos del centro y este de la parroquia estaban ocupados por medianas explotaciones familiares policulturales (olivos y almendros asociados al cereal) y un gran número de pequeñas explotaciones vitícolas. En 1667 la parroquia tenía 1.847 habitantes, distribuidos entre la villa de Binissalem y los caseríos de Lloseta y Aiamans ${ }^{12}$.

9. ACM, 14204 (1658), f. 66/20.

10. Véase la estimación realizada por los peritos para su división en 1687 (ACM, 14.165).

11. Una detallada descripción puede encontrarse en la cabrevación de 1658 (ARM, ERC-1169, f. 165).

12. Sobre la estructura de la propiedad en Binissalem véase PASCUAL (2009). 
La hacienda Safortesa estaba administrada por el presbítero Jaume Antoni Rubí. Este era el encargado de llevar los libros de cuentas, trasmitir las órdenes del terrateniente a los diversos arrendatarios y mayorales, y supervisar la gestión de todos los predios de la hacienda ${ }^{13}$. El manejo de los cultivos estaba a cargo de un mayoral que junto a su esposa e hijos habitaban permanentemente en el predio ${ }^{14}$. La explotación del predio se dividía en diversas unidades gestionadas de manera diversa, pero coordinada. Por una parte, se arrendaban los aprovechamientos silvícolas de los bosques (carboneo y cal) y los pastos junto al predio Son Fuster de Palma ${ }^{15}$. Dentro del mismo predio se arrendaban también los rafales de Son Daviu y El Rafalet, medianas explotaciones policulturales de unas cuatro hectáreas cada una, el huerto de Son Cocó, y el molino y huerta que estaban situados sobre el torrente de Almadrà ${ }^{16}$.

Los propietarios del predio explotaron entre 1657-1658 y 1683-1684 directamente los olivares, las sementeras de cereales, los huertos y las viñas. Los olivos se cultivaban asociados a los cereales en las tierras más feraces del valle (tanques), mientras que la intensidad de la asociación disminuía en las vertientes de la sierra. El aceite constituía con diferencia el principal aprovechamiento del predio, con una producción media en el período de 7.700 cuartanes (30.000 litros). La mayor parte del aceite era vendido en el mercado de Palma, desde donde se despachaba a los mercados mediterráneos y atlánticos ${ }^{17}$. En cambio, el producto de las sementeras se destinaba al consumo de los trabajadores y la familia del propietario (vino, hortalizas, trigo), o del ganado de labor (algarrobas y cebada $)^{18}$.

13. Este fue administrador de este predio y otros de la hacienda entre 1652-1687 (ACM, 14204, ff. 4 ss.; ARM; PN, S-90, f. 13; M-95, f. 132).

14. A lo largo del período estudiado el predio fue conducido por Jaume (no consta el apellido), su mujer Matgina, y su hijo Gabriel de Alaró (1658-1666), Joan Perelló Sastre de Llubí (1666-1669), Antoni Albertí de Banyalbufar (1669-1670), Pere Bibiloni de Santa Margalida (1670-1671), Joan Reus (1671-1672) y Antoni Pericàs de Consell (1672-1679). Aparte de la familia del mayoral, también se contrataban algunas mujeres para ayudar en la cocina y otras labores domésticas. Esta fuerza de trabajo no ha sido integrada en el estudio.

15. ARM, PN, T-998, f. 68.

16. ACM 14.204 ff. 25v, 46v, 93v, 94 .

17. Información procedente de las cuentas de 1652-1656 (ACM, 5494) y la estimación de la producción y valor del predio realizada en 1684 (ARM, Audiencia [AA], 96. Pleitos sobre las mejoras realizadas en el predio de S'Estorell, 1688).

18. No se documenta la venta o compra de trigo, pero sí que era frecuente la compra de cebada y avena para alimentar al ganado de tiro. Además, se compraron de forma intermitente otros alimentos como carne, queso, higos, uva y vino, cuando la producción del predio era insuficiente. Durante la etapa 1658-1679 el gasto destinado a la compra de cereales para el ganado representó la mitad del gasto monetario total del período (ACM, 14.193). 


\subsection{Modalidades contractuales y ocupación}

Para la explotación del predio se contrataba mano de obra fija y jornalera. En la elección de la mano de obra el propietario y el administrador recurrían a las informaciones que les proporcionaban gente de confianza de las villas próximas ${ }^{19}$. La práctica totalidad de las cogedoras de aceitunas eran contratadas en cuadrillas articuladas mayoritariamente en torno a grupos familiares. Los acuerdos se realizaban mediante mujeres que organizaban las cuadrillas en las villas (Jover, 2015). Las cuadrillas de jornaleros para las diferentes labores eran contratadas mediante la intermediación de capataces ${ }^{20}$, aunque en ocasiones, como los contratos para la siega, la labor se ofrecía al mejor postor en la plaza de la villa ${ }^{21}$.

\section{CUADRO 1}

Número de personas y días de trabajo contratados en S'Estorell, entre $1658-1659$ y $1672-1673$

\begin{tabular}{lccccc}
\hline Personas & $\begin{array}{c}\text { Número de personas } \\
\text { contratadas anualmente }\end{array}$ & $\begin{array}{c}\text { Total } \\
\text { jornales/año }\end{array}$ & $\begin{array}{c}\text { Media jornales } \\
\text { persona }\end{array}$ & $\begin{array}{c}\text { \% Número } \\
\text { personas }\end{array}$ & $\begin{array}{c}\text { \% Número } \\
\text { jornales }\end{array}$ \\
\hline Mozos & 29 & 4.249 & 148 & 17,9 & 39,7 \\
Mano de obra masculina* & 49 & 1.292 & 34 & 30,2 & 12,1 \\
Mano de obra femenina & 65 & 4181 & 64 & 40,1 & 39,1 \\
Mano de obra infantil & 11 & 630 & 60 & 6,8 & 5,9 \\
Oficios hombres & 7 & 329 & 50 & 4,3 & 3,1 \\
Hilar mujeres & 1 & 10 & 10 & 0,6 & 0,1 \\
Total & $\mathbf{1 6 2}$ & $\mathbf{1 0 . 6 9 2}$ & $\mathbf{6 6}$ & $\mathbf{1 0 0 , 0}$ & $\mathbf{1 0 0 , 0}$ \\
\hline
\end{tabular}

Nota: cálculo sobre los quince años con información completa.

^El cálculo del número de activos jornaleros se ha estimado a partir del promedio de individuos que integraban las cuadrillas.

Fuente: ACM, 14204, 14193 y 16922.

El Cuadro 1 sintetiza el número de personas y los días trabajados en promedio para el período $1658-1659$ y 1672-1673 y para cada una de las categorías laborales. A lo largo

19. Así se desprende de las cartas cruzadas entre el terrateniente y su administrador, en el pliego de albaranes adjunto al libro de cuentas de 1671-1680 (ACM, 14.193).

20. En los acuerdos con estas cuadrillas el administrador anotaba en primer lugar el nombre del capataz, y en ocasiones los nombres de los integrantes de la cuadrilla, aunque en la mayoría de las ocasiones se refería a sus integrantes como altres homes ("otros hombres»). Muchas de estas contrataciones se realizaban por mediación de un mayoral o mozo del predio, como se muestra en las cartas entre el propietario y el administrador (ACM, Libro de cuentas, 14204).

21. ARM, Torrella (Archivo Torrella), Ar 10, Fa 21, pliego de cuentas de la administración de S'Estorell, $\mathrm{s} / \mathrm{n}$, números de los registros de gasto 11 y 12 . 
del período estudiado se contrataban anualmente en promedio 162 personas que realizaban 66 jornales cada uno, y en total 10.692 jornales. Cada año se contrataban de media 29 mozos, que trabajaban 148 días, representaban el $22 \%$ de las personas contratadas y cerca del $40 \%$ del total de días de trabajo. Estos desempeñaban una gran variedad de labores: labrar los campos, trabajar en las viñas y huertos, la elaboración del aceite y el cuidado del ganado de labor, y también realizaban labores junto a la mano de obra jornalera (Jover, Pujadas \& Suau, 2017). Por lo que se refiere a la mano de obra jornalera, el contingente de trabajo más importante eran las mujeres (65) y niños (11), que conjuntamente aportaban el $45 \%$ de los días de trabajo anuales del predio. También se contrataban 49 jornaleros anualmente, que contribuían con el $12 \%$ de los días de trabajo, y de media trabajaban 34 días. Por último, las labores de los artesanos para el mantenimiento del instrumental de trabajo (capazos, herramientas, etc.), infraestructuras (terrazas y sistema de drenaje) e instalaciones (reparación almazara y casas) correspondían cada año a un herrero, un carpintero, un espartero y una cuadrilla de albañiles. A su vez, una o dos mujeres, aunque para unos pocos días, eran contratadas para hilar la seda que se producía en el predio.

\section{CUADRO 2}

Modalidades contractuales de la mano de obra de S'Estorell, 1658-1673, 1674-1675 y 1677-1680

\begin{tabular}{|c|c|c|c|c|}
\hline Gasto monetario en salarios & Total\% & Destajos\% & Jornal\% & Meses\% \\
\hline Femeninos e infantiles & 45,70 & 0,10 & 45,80 & \\
\hline Masculinos & 46,30 & 7,60 & 35,30 & 3,40 \\
\hline Mixtos & 8,00 & 8,00 & & \\
\hline Total & 100,00 & 15,70 & 80,90 & 3,40 \\
\hline Número de jornales contratados & Total\% & Destajos\% & Jornal\% & Meses $\%$ \\
\hline Femeninos e infantiles & 67,80 & 0,10 & 67,90 & \\
\hline Masculinos & 28,90 & 2,90 & 22,10 & 3,90 \\
\hline Mixtos & 3,30 & 3,30 & & \\
\hline Total & 100,00 & 6,30 & 89,80 & 3,90 \\
\hline
\end{tabular}

Nota: Se diferencia entre gasto monetario y jornal. Fuente: ACM, 14204, 14193 y 16922.

El resultado era una demanda de trabajo relativamente compleja que incluía un contingente de trabajadores fijos, los mozos, y otro de casuales (mano de obra jornalera), que atendían las labores estacionales. Si bien no forman parte de este análisis, los mozos constituían la fuerza de trabajo permanente y más estable del predio, y eran contratados para todo el año, o por labores estacionales como labrar o fabricar el aceite (Jover, Pujadas \& Suau, 2017). La mano de obra jornalera era pagada por día de trabajo 
efectivo, aunque la relación contractual se podía prolongar a lo largo de semanas e incluso meses.

Los contratos de la mano de obra jornalera tomaban diversas modalidades atendiendo a consideraciones técnicas y sociales (Carmona \& Simpson, 2003). En general, se ha considerado que el contrato a destajo, por labor realizada, se utilizaba mayoritariamente en labores poco cualificadas, intensivas en trabajo y que exigían rapidez en su ejecución, y tenían bajos costes de supervisión (labores de cavar, entrecavar, desbrozar u otras similares); reservándose la contratación de mano de obra a jornal a las labores especializadas y que tenían una mayor afectación sobre los bienes fondo (injertar, podar y plantar). En el predio estudiado se observaron esas diferentes modalidades contractuales (destajo, contrato por días o jornal) y también un contrato para las mismas labores dadas a destajo o jornal que se pactaba por meses. En el Cuadro 2 se presentan esas modalidades ordenadas por contrato y género, y expresadas en el porcentaje del valor monetario de los salarios (panel superior) y días de trabajo (panel inferior) respecto del total para el periodo estudiado.

El contrato a jornal era claramente dominante en la práctica totalidad de labores: el $81 \%$ del gasto y el $88 \%$ de los días de trabajo, ya fuesen labores no cualificadas (coger aceituna, entrecavar cereales, cavar pies, etc.) o cualificadas (injertar olivos, podar viñas y olivares). La contratación por meses representaba un 3,4\% del gasto y el 3,9\% de los jornales totales. En esta modalidad, que consistía en dar a una cuadrilla la labor de cavar los pies o entrecavar y que duraba algunos meses, el salario monetario pactado para cada miembro era equivalente al de un mozo del predio (35-40 sueldos al mes), aunque no se especifica en los libros de cuentas si se les proporcionaba la manutención. El administrador, en una carta fechada en 1669, le explicaba al conde que había hecho un contrato por meses a diversos jóvenes de las villas del centro de la isla, pues los previamente contratados de las villas próximas al predio no se habían presentado, al considerar que el precio del jornal diario ofrecido era insuficiente ${ }^{22}$.

Los contratos a destajo representaban el 15,7\% del gasto y un 6,3\% del número de días de trabajo. Las mujeres aparecen en escasas ocasiones contratadas a destajo: un 0,1\% en términos de gasto y número de jornales. Los destajos se concentraban en labores duras y que exigían urgencia en su desempeño. Este era el caso de la siega, que en prácticamente todos los años del período estudiado se dio a destajo. En el desbroce de las sementeras y cavar los pies de los olivos se combinaba el trato a jornal y a destajo. Ambas labores eran intensas y tenían un plazo de ejecución: la primera tenía que haber concluido

22. ACM, 14.193, sin foliar. 
antes del inicio de la recogida de las aceitunas, a principios de octubre, y la segunda en enero. Para incentivar su ejecución, se pactaba un precio al inicio de la campaña para cada sementera o zona a desbrozar en función de la extensión y dureza del trabajo, y los pagos se efectuaban a medida que el trabajo avanzaba a compte ("a cuenta») y, el último, $a$ compliment ("a cumplimiento») cuando se había terminado la labor ${ }^{23}$. El motivo por el que se combinaba el destajo y el jornal en esas labores en un mismo año se recoge implícitamente en los registros de los libros de cuentas. Las anotaciones sugieren que las zonas dadas a jornal se correspondían con las tanques, las tierras más feraces en las que el cultivo de trigo y cebada se asociaba al olivar, cercanas a las casas del predio y sobre las que los costes de supervisión eran bajos. Mientras que el desbroce a destajo se reservaba para las tierras más alejadas y recientemente roturadas ${ }^{24}$. Por tanto, en esas labores se combinaba la eficiencia, los costes de supervisión con los incentivos para realizar una labor más cuidadosa en las aéreas de cultivo intensivo.

El contrato por días era ampliamente predominante, mientras los destajos representaban una pequeña proporción del número de personas y jornales contratados. Esta preponderancia de la contratación a jornal posiblemente estaba relacionada con la amplia oferta de trabajo asalariado disponible, debida a la creciente desigualdad en el acceso a la tierra y a la progresiva desaparición de las alternativas laborales a las actividades agrarias en el conjunto de la sociedad rural, básicamente debido al declive de la manufactura rural de la lana a partir de la década de 1630 (Deyá, 1998). Sin embargo, la combinación de diversas modalidades contractuales, para un mismo año y labor, merece una mayor atención de la que se le ha prestado hasta ahora, para entender la lógica de la contratación del trabajo en el marco de las diversas presiones sociales y técnicas que afectaban al manejo de los cultivos (Bardhan, 1984).

\subsection{La demanda estacional de trabajo: labores, sexo y edad}

En los cuadros 1 y 2 se ponía ya de relieve la importancia que tenía la mano de obra femenina en la demanda total de trabajo. El propósito de este apartado es especificar cuáles eran las labores que daban esa centralidad a la mano de obra femenina y en menor medida infantil, y en segundo lugar comprobar si la complementariedad en la demanda

23. Véase una muestra de esos contratos y pagos en S'Estorell en ACM, 14.204, f. 41 y ARM, Torrella, Ar 10, Fa 21, pliego de cuentas de la administración de S'Estorell, s/n, en el apartado Descarrech de los olivos.

24. Véanse, por ejemplo, los contratos en Son Pont y Galatzó de los años 1631-1633 (ACM, 14.197) y en las cuentas de 1663 de Son Pont y Son Tugores (ACM, 19.623). 
de los sistemas agrícolas de olivar y cereal era uno de los factores que contribuían a la especialización regional de esos dos sectores (Juan Vidal, 1989: 170).

El Cuadro 3 distingue la distribución de la demanda de trabajo a jornal por sexo, edad y labor en los principales cultivos. El olivar absorbía prácticamente el $90 \%$ del trabajo a jornal; a mucha distancia le seguían en importancia el cultivo de los cereales $(6,8 \%)$ y las labores en las huertas y viñas $(1,8 \%)$. Esas labores eran realizadas en un $69,8 \%$ por mano de obra femenina, en un 20,5\%, masculina adulta, y en un 9,75, infantil. Así pues, la feminización del trabajo jornalero era muy elevada, aunque como veremos muy desigualmente distribuida entre labores y cultivos.

\section{CUADRO 3}

Distribución de la mano de obra jornalera por labores y sexo. S'Estorell, $1658-1673,1674-1675$ y 1677-1680

\begin{tabular}{lcccr}
\hline Labores & Femenino & Infantil & Masculino & Total \\
\hline Entrecavar cereales & 0,8 & 0,1 & 1,4 & 2,2 \\
Preparar y esparcir abono & & & 0,3 & 0,3 \\
Siega mixto & 2 & & 2,1 & 4,1 \\
Viña y huerta & 0,1 & & 1,2 & 1,3 \\
Cavar olivos y viña & & 5,2 & 5,2 \\
Desbrozar olivares & & 5,5 & 5,5 \\
Injertar olivos & & & 0,7 & 0,7 \\
Podar olivos y viña & & & 3,3 & 3,3 \\
Varear algarrobos & & & 0,8 & 0,8 \\
Coger aceitunas & 62,9 & 9,5 & & 72,3 \\
Coger algarrobas & 4 & 0,2 & & 4,2 \\
Totales & $\mathbf{6 9 , 8}$ & $\mathbf{9 , 8}$ & $\mathbf{2 0 , 5}$ & $\mathbf{1 0 0 , 0}$ \\
\hline
\end{tabular}

Nota: porcentajes respecto del número total de jornales.

Fuente: ACM, 14204, 14193 y 16922.

La mano de obra femenina e infantil se destinaba prácticamente en su totalidad a la recogida de las aceitunas y las algarrobas ( $67 \%$ y $9,8 \%$, respectivamente) y casi no participaba en las labores de mantenimiento del suelo y copa de los olivares, viña y algarrobos, exceptuando en las labores de entrecavar la viña y cereales. Por el contrario, la mano de obra masculina era contratada para las labores más especializadas de la copa de los olivares y varear algarrobos (casi el 5\%, con predominio de la labor de podar), pero también para las labores no cualificadas de suelo en el olivar, como desbrozar y cavar los pies (algo más del 10\%), y también desempeñaba el grueso de las tareas de entrecavar y abonar las sementeras de cereales (2,5\% del total). En la siega, sin embargo, la contratación 
de mano de obra femenina representaba la mitad de los efectivos de las cuadrillas, aunque una proporción menor en cuanto a los días de trabajo (cerca del 44\%). Es probable que esta proporción a mediados del siglo XviI fuese mucho más elevada que en los siglos XVIII y $\mathrm{XIX}^{25}$.

\section{GRÁFICO 1}

\section{Estacionalidad del trabajo por sexos. S'Estorell, 1658-1673}

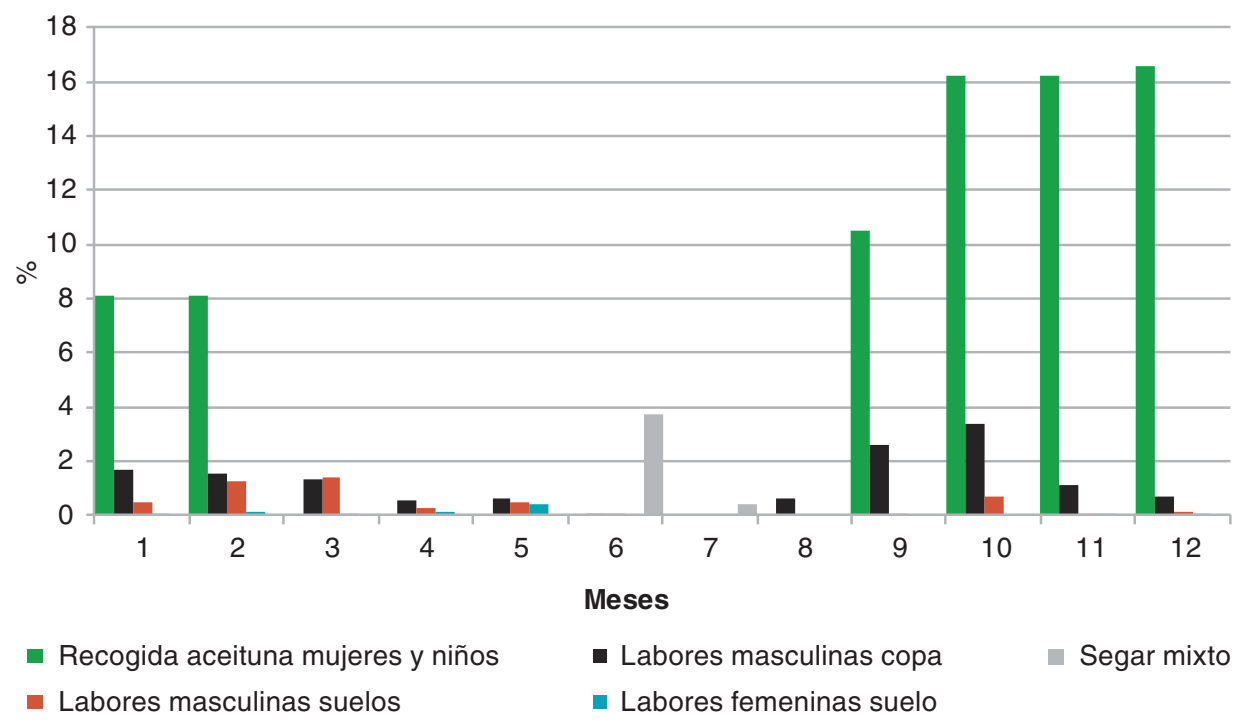

Nota: los porcentajes se han calculado sobre el número de días de trabajo por labor y sexo respecto del total de días de trabajo del período (100= media mensual 1658-1673).

Fuente: ACM, 14204, 14193 y 16922.

Los roles laborales asignados a hombres y mujeres que hemos descrito para el predio S'Estorell coincidían a grandes rasgos con los descritos en otros trabajos (Grau \& Tello, 1985; Albertí \& Morey, 1986). No obstante, esos roles podían romperse cuando la concurren-

25. Véanse las hojas de albaranes y correspondencia en ACM, 14193. En 1632 en Son Pont la cuadrilla de segar estaba integrada por mujeres, mientras los hombres trillaban (libros de cuentas de Son Pont y Galatzó, 1631-1634, en ACM, 14196). En los predios de Son Costa la proporción de jornales de siega realizados por mujeres era de un $25 \%$ del total a finales del siglo XVI, en su mayor parte destinados al espigueo. Sin embargo, a mediados del siglo XVII la proporción de jornales femeninos en la siega en el predio de Son Gallard era del 75\% y en Son Costa era de cerca del 55\% (Jover \& Pons, 2012: 215-216). En el siglo XVIII los predios de Son Costa muestran una proporción mayoritaria de trabajo masculino, aunque los destajos en los que no se diferenciaba el trabajo por géneros ensombrecen los datos (Jover, 2013a: 256). En cambio, según el interrogatorio de 1850, las mujeres solamente representaban en los distritos cerealistas el $15 \%$ de los jornales destinados a la siega (Tello, 1983: 75-78). 
cia de diversas demandas de trabajo para labores diferentes en la misma estación lo exigían. El Gráfico 1 presenta el número de jornales medios por labor y género expresados en porcentajes respecto de la media del período. En los meses de septiembre a enero la mano de obra femenina e infantil era absorbida en su práctica totalidad primero por la recogida de la algarroba (septiembre) y posteriormente para la aceituna entre octubre y enero, o hasta que finalizaba la campaña en años de cosechas excelentes. Cuando terminaba la recogida de las aceitunas, en enero o febrero, las mujeres se incorporaban a la escarda de primavera para los cereales, generalmente en abril y mayo. Las labores masculinas se iniciaban en agosto con el desbroce del olivar (de agosto a octubre), y continuaban en los meses de noviembre a enero con la cava de los pies de los olivos, que se simultaneaba con entrecavar las sementeras de trigo. En febrero, la mano de obra masculina se incorporaba a las labores de poda de los olivos (febrero a abril) y al injerto de los olivos (mayo). En verano la demanda de mano de obra agrícola se concentraba en la siega, aunque esa era una época importante de demanda de mano de obra para otras actividades silvícolas, como la fabricación de carbón vegetal.

La estacionalidad de las labores por género, sin embargo, presenta una anomalía destacable cuando la comparamos con la de los predios cerealistas. Los predios del convento de Santo Domingo (Palma), que poseía en la parroquia de Montuïri, en el corazón cerealista de la isla, muestran un patrón muy similar al descrito para S'Estorell: cerca del $44 \%$ de los días de trabajo totales lo aportaban los mozos, y el 56\% la mano de obra jornalera. La mano de obra femenina representaba el $75 \%$ de los días de trabajo, los jornales masculinos cerca del $17 \%$ y la mano de obra infantil estaba prácticamente ausente en los libros de cuentas (Jover \& Pons, 2012: 203-224; Jover, 2013b: 245-253). En los predios cerealistas la máxima demanda de trabajo femenino se producía entre el otoño y la primavera, cuando se desterronaban los campos (septiembre), y tras la siembra se iniciaban las labores de entrecavar en otoño e invierno (Tello, 1983). De esta manera, aunque no coincidían los picos de cosecha en uno y otro sector, en los meses de otoño e invierno concordaba la demanda de trabajo para la recogida de la aceituna en los olivareros y para entrecavar las sementeras sembradas de trigo en los predios olivareros y también cerealistas (Gráfico 1). Por tanto, en otoño-invierno se producía una intensa concurrencia de labores desmintiendo la complementariedad en la demanda de trabajo entre los predios cerealistas y olivareros sugerida en otros trabajos.

Esta convergencia de demandas planteaba diversos problemas a los terratenientes olivareros. En primer lugar, la intensa demanda de mujeres para la recogida de la aceituna exigía contratar a hombres para labores de entrecavar en otoño e invierno, pues las mujeres solamente se incorporaban a la escarda de primavera cuando la recogida de aceitunas había finalizado, lo cual equivalía a romper las «reglas de género» en la tradicional dis- 
tribución de las labores. En segundo lugar, los terratenientes tenían que bombear todas las reservas de trabajo «barato» disponibles (mujeres y niños) de los mercados locales, y si estos eran insuficientes dirigirse a los mercados regionales. Por último, era preciso ofrecer salarios suficientemente atractivos para retener y atraer la mano de obra necesaria para la recogida de la aceituna y otras labores, en unos mercados donde también existían otras demandas de trabajo en esos meses.

\subsection{Mercados de trabajo: cerca y lejos}

Como se ha sugerido en diversos puntos del artículo, no toda la mano de obra era contratada en el mercado local, entendido este por el territorio que comprendía la parroquia de Binissalem y las limítrofes de Selva, Alaró y Sencelles. ¿De dónde procedía la mano de obra contratada en el predio S'Estorell? En el Cuadro 4 se ha organizado la información sobre la procedencia de la mano de obra de S'Estorell atendiendo al número de jornales realizados por la mano de obra jornalera contratada. El cuadro se ha ordenado por las parroquias de procedencia (entre paréntesis se ha especificado la villa o aldea de donde era originaria), a continuación, la comarca, la distancia del lugar de procedencia respecto del predio, y en columnas se han ordenado el porcentaje de los jornales femeninos (segunda columna) y masculinos (el resto) respecto del total de cada labor.

A mediados del siglo XVII los estudios sobre la estructura demográfica y urbana (Segura \& Suau, 1984), la distribución de la propiedad y explotación de la tierra (Montaner \& Morey, 1989; Suau, 1991), las actividades manufactureras rurales (Segura \& Suau, 1981; Deyá, 1998) y los paisajes agrarios (Bisson, 1977; Juan Vidal, 1989; Manera, 2001) permiten distinguir las siguientes comarcas agrosociales (Mapa 1). El distrito del Raiguer, donde se ubicaba el predio S'Estorell, estaba situado al pie de la sierra, y se caracterizaba por un claro predominio de la pequeña y mediana propiedad con una intensa especialización vitícola, mientras en las vertientes de la sierra se situaban los predios olivareros. La sierra de Tramuntana se caracterizaba por el predominio de la gran propiedad y la especialización olivarera. En el Pla la estructura de la propiedad estaba muy polarizada entre las grandes explotaciones cerealistas y las pequeñas explotaciones campesinas que rodeaban las villas. Por último, en los distritos de Llevant, al nordeste, y Migjorn, en el sudeste, predominaban las extensas haciendas destinadas a los aprovechamientos agropastorales y la pequeña propiedad campesina se concentraba alrededor de centros urbanos compactos. 


\section{CUADRO 4}

Porcentaje de jornales de cada labor por áreas de reclutamiento.

S'Estorel1, 1658-1674

\begin{tabular}{|c|c|c|c|c|c|c|c|c|c|}
\hline \multirow[b]{2}{*}{ Parroquia } & \multicolumn{2}{|c|}{$\begin{array}{c}\text { Áreas de } \\
\text { reclutamiento }\end{array}$} & \multirow{2}{*}{$\begin{array}{c}\text { Jornales femeninos } \\
\text { e infantil (\%) } \\
\text { Coger } \\
\text { aceitunas }\end{array}$} & \multirow{2}{*}{$\begin{array}{c} \\
\text { Cavar } \\
\text { pies }\end{array}$} & \multicolumn{5}{|c|}{$\begin{array}{c}\text { Jornales } \\
\text { masculinos (\%) }\end{array}$} \\
\hline & Comarca & $\begin{array}{l}\text { Distancia al } \\
\text { predio (km) }\end{array}$ & & & Desbrozar & Injertar & Podar & $\begin{array}{c}\text { Entrecavar } \\
\text { y abonar }\end{array}$ & Total \\
\hline Artà & Llevant & 51,5 & 0,5 & & & & & 2,1 & 0,2 \\
\hline Felanitx & Migjorn & 45,8 & 3,3 & 0,2 & 0,8 & & & & 0,3 \\
\hline Llucmajor & Migjorn & 31,1 & & & 0,7 & & & 1,5 & 0,3 \\
\hline Montuïri & $\mathrm{Pla}$ & 26,8 & 0,1 & 3,0 & 0,1 & 1,6 & & 4,8 & 2,0 \\
\hline Muro (Llubí) & $\mathrm{Pla}$ & 26,7 & 4,6 & & & & & & \\
\hline Petra & $\mathrm{Pla}$ & 31,6 & & & & & & 1,3 & 0,1 \\
\hline Sa Pobla & $\mathrm{Pla}$ & 20,3 & 10,4 & & & & & & \\
\hline Santa Margalida & $\mathrm{Pla}$ & 27,6 & 52,9 & 21,5 & & & & & 6,1 \\
\hline Sineu & $\mathrm{Pla}$ & 20,3 & & & & & & 1,8 & 0,2 \\
\hline Sencelles & $\mathrm{Pla}$ & 13,6 & 1,4 & 11,9 & & & & 9,2 & 4,3 \\
\hline Binissalem & Raiguer & 6,8 & 7,6 & 27,0 & 40,7 & 52,1 & 33,1 & 43,3 & 38,0 \\
\hline Inca & Raiguer & 7,6 & & & & & & 0,4 & \\
\hline Alaró & Serra & 7,5 & 1,7 & 4,4 & 45,9 & 43,1 & 1,1 & 13,4 & 19,9 \\
\hline Selva (Mancor) & Serra & 11,4 & 6,0 & 9,8 & 5,1 & & 55,8 & 16,8 & 15,4 \\
\hline Valldemossa & Serra & 31,6 & & 0,1 & 0,3 & & & & 0,1 \\
\hline Menorca & & - & & 10,3 & & & & & 3,0 \\
\hline No Identificado & & - & 10,8 & 11,9 & 6,4 & 3,2 & 10,0 & 5,5 & 10,0 \\
\hline Total & & & 100,0 & 100,0 & 100,0 & 100,0 & 100,0 & 100,0 & 100,0 \\
\hline
\end{tabular}

Fuentes: Cuadros 1 y 2.

La segunda columna muestra la distribución de la contratación de la mano de obra femenina e infantil para la recogida de la aceituna. Un 7,6\% se contrataba en Binissalem, parroquia donde se ubicaba el predio, y en proporciones menores en las parroquias colindantes de Selva, Alaró y Sencelles (en su conjunto, poco más del 9\%). El trayecto entre esas villas y el predio se realizaba a pie en algo más de una hora y permitía ir cada día de casa al tajo. Este contingente de cogedoras, que era contratado en el mercado local, suponía en torno al $18 \%$ del total; el resto de las cogedoras se contrataba en el mercado regional. El $68 \%$ de las cogedoras procedían de las villas del centro de la isla, de las cuales solo la parroquia de Santa Margalida aportaba el 53\% de los efectivos, muy por encima de otras villas del Pla, como Sa Pobla o Muro, que representaban el 15\%. Estas villas estaban situadas a más de veinte kilómetros de S'Estorell, con trayectos a pie de más de 6 horas, y en otros de 46-52 kilómetros, que suponía andar unas once horas. 


\section{MAPA 1}

\section{Localizaciones de los distritos agroecológicos y municipios de origen} de la mano de obra jornalera de S'Estorell en la Mallorca moderna

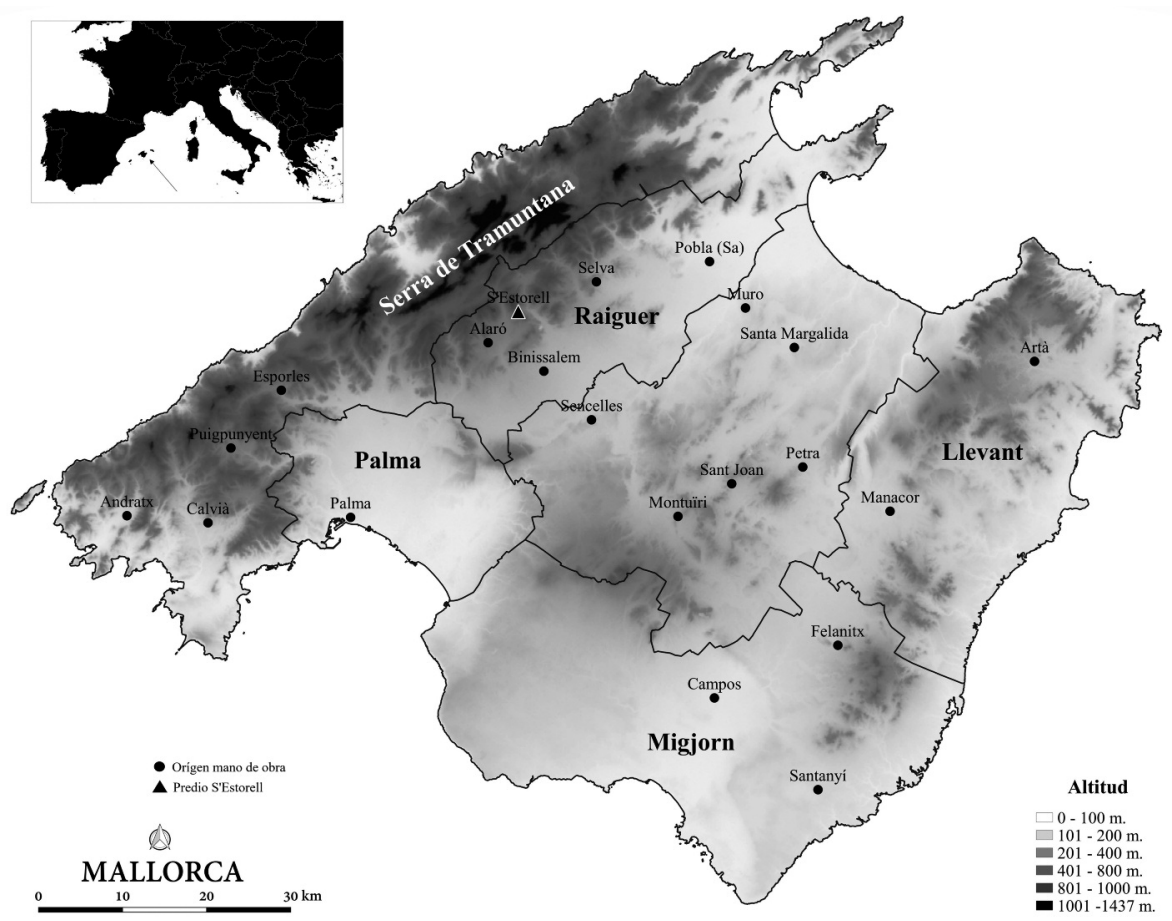

Fuente: elaborado a partir de las capas base históricas creadas por Ivan Murray (Tello et al., 2018).

El mercado de reclutamiento de la mano de obra masculina tenía un carácter eminentemente local. Las tres cuartas partes de la mano de obra masculina procedían de Binissalem o de los pueblos vecinos de Sencelles, Selva y Alaró. Los trabajadores destinados a desbrozar e injertar procedían en más del $80 \%$ de las villas de Alaró y Binissalem; los podadores en un $89 \%$ residían en Selva y Binissalem; aunque para algunas labores relativamente intensivas en trabajo (como cavar los pies) se contrataron cuadrillas en Santa Margalida (21,5\%), Menorca $(10 \%)^{26}$, y otras villas del centro de la isla como Montuïri, Sineu, Petra y Llucmajor, en una proporción nada despreciable.

Así pues, el reclutamiento en los mercados local y regional respondía a propósitos económicos y logísticos diferentes. En el caso de las cogedoras de aceitunas, la contratación

26. En este caso se trata de los mismos individuos que se habían contratado como mozos y jornaleros en S'Estorell (Jover, Pujadas \& SuAu, 2017). 
en el mercado local garantizaba el trabajo en el inicio de la recogida y la rebusca al final de la campaña, y aseguraba un contingente de mano de obra mínima en los años de pésimas cosechas ${ }^{27}$. Mientras que en los años de buenas cosechas la demanda concurrente de los predios olivareros de la sierra vaciaba el mercado local, y exigía que los terratenientes con predios más extensos y con rendimientos elevados tuvieran que recurrir al mercado regional para cubrir la larga temporada de la recogida de la aceituna. En la contratación de mano de obra masculina para algunas labores (cavar y entrecavar) el terrateniente recurría al mercado regional solo ocasionalmente, cuando la oferta local exigía salarios muy elevados, como se ha mostrado.

La comparación entre la parroquia donde se ubicaba el predio S'Estorell y aquella de donde procedían la mayor parte de las cogedoras ofrece una primera aproximación a la explicación de esos movimientos migratorios. La parroquia de Binissalem estaba densamente poblada, se había consolidado una amplia capa de pequeños y medianos propietarios, en sus tierras orientales se había desarrollado una creciente especialización vitícola y pervivían ciertas actividades manufactureras (Pascual, 2009). Por tanto, la especialización olivarera de los predios de la vertiente de la sierra, por un lado, y la demanda de trabajo de las explotaciones vitícolas, por otro, posiblemente obligaban a los terratenientes a recurrir a mercados de trabajo más amplios. Por otra parte, Santa Margalida, la parroquia de donde procedían la mayor parte de las cogedoras y también la mano de obra masculina protagonistas de esos movimientos estacionales, era una zona especializada en la producción de cereales y sin presencia significativa de actividades manufactureras. Además, la tierra estaba muy desigualmente repartida. La mayor parte de la tierra era poseída por la aristocracia, entre la que se encontraba el conde de Formiguera, propietario de S'Estorell, que además poseía la jurisdiccional feudal sobre una parte importante de la parroquia. En las décadas de 1630 a 1650 la presión señorial y la renuencia de los terratenientes a establecer tierras habían provocado numerosos conflictos, y empujado incluso a una parte de la población a la emigración definitiva a tierras valencianas. En este caso operaban todos los factores para la expulsión: pobreza, escasas alternativas al trabajo agrícola y el poder de negociación de los terratenientes redoblado mediante el control sobre el acceso a la tierra y el ejercicio del poder jurisdiccional (Montaner \& Le Senne, 1977; Mas-Forner, Monjo \& Mas, 2009).

Por tanto, la desigualdad en la distribución de la tierra y la especialización agrícola pudieron tener un papel importante en esos movimientos migratorios estacionales. Sin embargo, este esquema no explica suficientemente por qué una parte de la mano de obra,

27. Por ejemplo, en S'Estorell se contrataba a las mujeres de Lloseta, la misma localidad donde se ubicaba el predio, o de las parroquias vecinas (ACM, 16923). 
aunque menor, procedía también de villas con una creciente especialización vitícola (Felanitx, Sencelles) o de cultivos de regadío (Muro y Sa Pobla), y en las que la desigualdad en la distribución de la tierra era menor. Por otra parte, los terratenientes para garantizar la mano de obra imprescindible para las labores en el olivar, y particularmente la recogida de la aceituna, necesitaban ofrecer a la mano de obra unos ingresos suficientemente elevados que compensasen esas migraciones estacionales, como se discutirá en el próximo apartado.

\subsection{Brecha salarial de género y skill Premium}

El propósito de este apartado es discutir el efecto que tuvo el sector exportador sobre el nivel de los salarios y, en particular, sobre la remuneración de las mujeres con respecto a los hombres para labores semejantes. Para ello, en el Cuadro 5 se comparan los salarios nominales de la mano de obra masculina y femenina adulta para las labores específicas del olivar del predio S'Estorell y de los predios de Son Costa, del convento de Santo Domingo situados en la parroquia de Montuïri (Jover \& Pons, 2012); esto es, de un gran predio olivarero y otros cerealistas del centro de la isla de donde procedía una parte significativa de la mano de obra contratada en S'Estorell. Para los propósitos de este estudio se analizarán los salarios medios del período 1661-1680 de ambos predios.

\section{CUADRO 5}

Salarios diarios medios de las labores más importantes en el manejo del olivar y cereales en S'Estorell (Binissalem) y los predios de Son Costa (Montuïri).

Media del período 1661-1680 en sueldos/día

\begin{tabular}{lccc}
\hline & \multicolumn{2}{c}{ S'Estorell (Binissalem) } & Son Costa (Montuïri) \\
\hline & Monetario & Total & Total \\
\hline Injertar olivos $^{*}$ & 6,20 & 7,70 & \\
Podar olivos $^{*}$ & 4,10 & 5,10 & \\
Cavar pies olivos $^{\prime}$ & 3,96 & & 3,36 \\
Entrecavar cereales $_{\text {Coger aceitunas* }}^{*}$ & 3,65 & & \\
Entrecavar & 1,13 & 1,41 & 1,17 \\
\hline
\end{tabular}

Nota: el asterisco $\left(^{\star}\right)$ significa que estaba acompañado de companatge. El salario completo es el resultado de sumar al salario monetario el valor del companatge, el complemento en especie.

Fuentes: libros de cuentas de S'Estorell, citados en el Cuadro 1; libros de cuentas de los predios de Son Costa, propiedad del convento de Santo Domingo, 1667-1685 (AH, C-163); y Jover y Pons (2012: 336337). 


\section{CUADRO 6}

Ratios salariales entre labores y brecha de género

en los predios de S'Estorell y Son Costa

\begin{tabular}{lr}
\hline Ratios salarios masculinos & $\%$ \\
\hline Injertar Estorell / Cavar pies Estorell & 169,9 \\
Injertar Estorell / Podar Estorell & 151,4 \\
Podar Estorell / Cavar pies Estorell & 103,4 \\
Cavar pies Estorell / Entrecavar Estorell & 108,5 \\
\hline Ratios salarios femeninos y masculinos & $\%$ \\
\hline Cavar pies Estorell / Entrecavar Son Costa & 118,03 \\
Entrecavar Estorell femenino / Entrecavar Estorell masculino & 37,81 \\
Entrecavar Son Costa femenino / Entrecavar Son Costa masculino & 34,7 \\
Coger aceitunas Estorell / Entrecavar Son Costa & 120,6 \\
\hline
\end{tabular}

Fuente: Cuadro 5.

A mediados del siglo XVII, en los predios de la hacienda Safortesa, los salarios se pagaban en metálico, en dinero corriente o en dinero y especies (manutención o aceite) cuando tenían un carácter mixto ${ }^{28}$. Solamente en algunos años el salario monetario se pagó en especies, en trigo a petición de la mano de obra ${ }^{29}$. Los pagos por las labores extras (a las vaciadoras de capazos en la recogida de la aceituna), anticipos (penyora) o pagos paternalistas por servicios prestados (regal) se consignaban al margen del salario pac$\operatorname{tado}^{30}$.

La jerarquía salarial y descripción de las labores en el olivar se encuentran recogidas en el tratado de agricultura de Montserrat Fontanet de 1747 (Juncosa \& Martínez, 1979) y el interrogatorio agrario de 1850 (Grau \& Tello, 1985). Las tareas de injertar y podar eran consideradas las más cualificadas. Ambas se pagaban con un salario mixto, compuesto por una remuneración en moneda y un complemento en especies llamado companatge ("condumio»), consistente en una cazuela con legumbres y hortalizas, acompañada de pescado salado o queso, vino, aceite y pan. El maestro era remunerado con 6 a 8 sueldos diarios en función del árbol (frutales, algarrobos u olivos), sus ayudantes (preparar el fango y la cuerda) percibían 4 sueldos diarios. El gasto en companatge en los años estudiados se calculaba en cerca de 1,5 sueldos por día, que elevaba el salario total del

28. La moneda era transportada por los trajineros en los frecuentes viajes entre la ciudad y los predios (ACM, 14197, ff. 1 y 4).

29. En 1669 se pagó a una parte de las cogedoras con trigo en vez de moneda (ACM, 16.922).

30. Por ejemplo, los complementos a las vaciadoras de capazos y a las mujeres que organizaban las cuadrillas (ACM, 16.922). 
maestro a 7,7 sueldos de media ${ }^{31}$. El salario diario de podar era notablemente inferior al de injertar: 4-5 sueldos diarios y la manutención se estimaba en 1 sueldo al día ${ }^{32}$. Las tareas de cavar pies y entrecavar los cereales se pagaban con salarios monetarios eixuts (sin complemento en especies), y pueden considerarse como el «salario mínimo» de la época, con una remuneración situada entre los 3,5 y los 4 sueldos diarios.

En el Cuadro 6 se han calculado los diferenciales entre las distintas labores masculinas. Los coeficientes muestran claramente que injertar olivos era con diferencia la labor mejor remunerada, porque exigía un mayor grado de experiencia. Las cuentas distinguían entre la labor del maestro, que decidía la modalidad de esqueje y las ramas, y las de sus ayudantes, que cobraban un salario inferior. La destreza y experiencia en esa labor debía ser muy apreciada, pues a lo largo de la etapa 1658-1680 solamente se contrataron dos maestros para realizar esa labor ${ }^{33}$. Por el contrario, la labor de podar era realizada por cuadrillas, sin que se hicieran distinciones salariales entre las labores de podar y recoger la leña. En los años centrales del siglo XVII, la poda no tenía la relevancia que adquirió en períodos posteriores, cuando los olivos eran más maduros y su rendimiento dependía de una poda más enérgica (Bisson, 1977; Grau \& Tello, 1985; Infante, 2014: 98-106). El salario era un 51\% inferior al de injertar, y entre un $29 \%$ y un 39\% mayor que las labores de cavar los pies y entrecavar, una diferencia claramente marcada por el pago de la manutención. Las labores de cavar los pies y entrecavar eran poco cualificadas, aunque el salario diario de cavar los pies era un $12 \%$ superior al de entrecavar. Esta diferencia estaba relacionada con el esfuerzo que exigía una y otra operación. Cavar los pies era una labor que se realizaba con una herramienta pesada, una azada ( $x a p a$ ). Su propósito era remover el suelo y eliminar los brotes nuevos que crecían en los pies de los olivos, mientras que entrecavar se realizaba con un escardillo ligero que servía para eliminar las hierbas adventicias en la sementera de cereales y facilitar la percolación de las lluvias. Por tanto, los salarios masculinos tenían una remuneración diferenciada según la destreza y dureza de la labor, pero además los salarios masculinos de cavar los pies en S'Estorell eran un 18\% más elevados que los de entrecavar en Son Costa. Como veremos, eso también sucedía en las labores femeninas.

31. En el predio Es Verger (Esporles), cercano a Son Tugores, el companatge consistía en legumbres, cebollas, queso y pescado salado, que se valoraban en 1,5 sueldos por trabajador y día. Véase el libro de cuentas de 1650 a 1663 (ARM, AH, C-4269, años 1651, 1652, 1663 y 1664).

32. Véase para S'Estorell, ACM, 5.228, libro de administración de la cosecha, 1645-1646, y ACM, 14.402; libros de cuentas de Son Pont y Galatzó, 1631-1634, en ACM, 14196 y 14197; libros de cuentas de Son Serralta, 1648-1649, en ARM, AMT, 133-M, 44/41; y para ElVerger el libro de cuentas ARM, C-4269.

33. La inversión en la expansión del olivar, construcción de terrazas e injerto de acebuches y olivos está descrita en el memorial de 1685 que recoge las inversiones realizadas por los propietarios desde 1652 (ACM, 14165). 
El abanico de salarios de la mano de obra femenina era muy reducido: coger aceitunas para las mujeres locales y las temporeras, y el salario de entrecavar los cereales en primavera (Cuadro 6, panel inferior). El salario de las cogedoras temporeras se establecía en el mercado regional, pues se contrataban a las cuadrillas en diversas villas por un mismo salario, como muestran los acuerdos salariales para los distintos predios de la hacienda del conde de Formiguera. Las cogedoras temporeras recibían un salario mensual mixto, una parte en moneda y la otra en especie (aceite), además de otros complementos, como alojamiento, leña, agua y el transporte de ida y vuelta de su residencia al predio ${ }^{34}$. El salario en especies consistía en una cantidad de aceite, entre dos y seis litros al mes, que podía suponer cerca del $20 \%$ de los ingresos totales. Por el contrario, las cogedoras contratadas por días en el mercado local cobraban únicamente un salario equivalente a la parte en metálico que cobraban las temporeras. El salario por labor de entrecavar los cereales en primavera era superior al que cobraban las cogedoras locales (Cuadro 3). La comparación relevante es la de los salarios pagados a las cogedoras de aceitunas del predio de S'Estorell y los que se pagaban por entrecavar en Son Costa en las mismas estaciones, otoño e invierno (Cuadro 6, Gráfico 1). El salario de ir a coger aceitunas era un $20 \%$ superior al de quedarse a entrecavar en los predios del término de residencia, en este caso Montuïri. Este diferencial, y tener cubiertos los costes de transporte y alojamiento, era el que pesaba en la decisión que debían tomar muchas familias de las villas del llano en otoño, cuando decidían dónde asignar los excedentes laborales familiares, qué miembros del hogar debían quedarse a entrecavar (Son Costa, Montuïri) y cuáles emigraban estacionalmente a coger aceitunas a la sierra (S'Estorell, Binissalem).

Por último, la brecha salarial de género entre hombres y mujeres para labores semejantes (entrecavar los cereales) en la sierra y el llano seguía siendo muy elevada. El salario femenino representaba menos del $40 \%$ del masculino. Esta brecha era semejante a la que había a mediados del siglo XvI (Jover \& Pons, 2012), y para períodos posteriores (Grau \& Tello, 1985; Albertí \& Morey, 1986; Escartín, 2001; Molina de Dios, 2003). La brecha únicamente era menor entre las cogedoras de aceitunas temporeras y el salario masculino de entrecavar. Solamente las condiciones excepcionales de la demanda de trabajo para la recogida de la aceituna, que llevaba pareja la movilización de mujeres de mercados regionales, tenían una compensación dentro del abanico salarial del mismo género: el salario de las cogedoras temporeras era superior al de las mujeres contratadas en los mercados locales.

34. Véanse los acuerdos salariales de las cogedoras de los años 1662-1665 y 1677-1679 de los predios de Galatzó, Son Togores y Son Pont en ACM, 16923. 


\section{DEMANDA DE TRABAJO, OCUPACIÓN FEMENINA Y BRECHA SALARIAL DE GÉNERO}

El análisis de la demanda y remuneración del trabajo en el predio S'Estorell ofrece algunos resultados peculiares y destacados respecto de otras trayectorias regionales en el ámbito europeo. En la isla, los mercados de trabajo estaban plenamente desarrollados a mediados del siglo XVII y tenían una estructura semejante a la del primer capitalismo agrario, donde la mano de obra jornalera o casual era predominante (Whittle, 2017: 1-18; Bavel, 2010: 201-213; Muldrew, 2011: 14-28). Los predios olivareros y cerealistas tenían una estructura de la demanda de trabajo muy semejante. Los mozos aportaban el 40\%-45\% de los días de trabajo y la mano de obra jornalera entre el 55\%-60\%. Sin embargo, las mujeres eran el principal contingente laboral de la mano de obra jornalera, con el $70 \%$ de los días de trabajo en ambos cultivos, aunque la mano de obra infantil tenía un peso más destacado en los predios olivareros, alcanzando prácticamente el 10\% del total. Así pues, el rasgo peculiar del capitalismo agrario isleño, frente a otros modelos de demanda de trabajo de la época, era la elevada feminización de la mano de obra jornalera. La proporción de la participación de las mujeres y los niños en los mercados de trabajo asalariado agrícola era superior a las que se registran en muchas regiones atlánticas, donde las mujeres alcanzaban menos del 30\% de la mano de obra contratada a jornal (Sharpe, 1995: 80-81; Burnette, 1999: 49-51; Yamamoto, 2004: 107-110; Hindle, 2013: 261; Gary, 2019: 12-13). Una situación similar, aunque en períodos posteriores, la encontramos en la España peninsular en zonas de predominio de mediana explotación (Lana, 1995: 142-143; 2000: 133-134, 144, 147; Fernández Romero, 2005: 48-55; Garrabou, Ramon-Muñoz \& Tello, 2015: 98) y de latifundio (Puntas \& López Martínez, 2000). Por lo que respecta a la composición de la demanda de trabajo específica del olivar, la división del trabajo por géneros en la isla era muy similar a otras regiones peninsulares (Martínez Soto, 2002; López Estudillo, 2006); aunque la asociación del cereal con el olivo y el sistema de recogida de la aceituna sin vareo exigía una mayor demanda de trabajo femenino que en otras regiones (Lobato, 1999; Borrero, 2003: 103-171; Infante, 2012). En cualquier caso, será necesario un trabajo más a fondo sobre las diferentes pautas de demanda regional de las explotaciones agrarias mediterráneas, en particular sobre la ocupación femenina, para evitar simplificaciones.

La especialización agrícola de los predios (olivareros versus cerealistas) en el caso estudiado no generó complementariedades en la demanda estacional de trabajo entre sectores, como se ha argumentado para las regiones atlánticas, aunque estudios más detallados pueden discutir esa hipótesis (Burnette, 2013: 135-164). Ello era debido a las condiciones del manejo del suelo en las zonas mediterráneas, donde cerrar los ciclos de nutrientes exigía una creciente asociación de cultivos y una mayor intensidad del trabajo 
(Fernández Prieto \& Soto, 2010). Así, el trabajo aumentaba proporcionalmente más en las labores de mantenimiento de los cultivos que en las de la cosecha (Tello, 1983; Sharp $\&$ Weisdorf, 2008). El resultado era una creciente concurrencia de las diversas demandas de trabajo agrario de los distintos cultivos en las mismas estaciones o meses (Fernández Romero, 2000; Vicedo, 2002). Ello provocaba ajustes en la demanda de trabajo de los terratenientes que tenían implicaciones sociales y geográficas. Por una parte, la demanda de trabajo vaciaba el mercado local de trabajo femenino, y requería que labores "tradicionalmente encomendadas a las mujeres", como entrecavar los cereales de invierno en los predios olivareros, fuesen realizadas por mano de obra masculina, invirtiendo así las «reglas de género» para atender a las necesidades estacionales de los distintos cultivos. Por otra parte, los terratenientes se veían impelidos a contratar en mercados más amplios la mano de obra necesaria para el manejo de los cultivos y la recogida de la aceituna. En cualquier caso, será necesario un trabajo más a fondo sobre las diferentes pautas de demanda regional de las explotaciones agrarias mediterráneas, en particular sobre la ocupación femenina, para evitar simplificaciones.

Los libros de cuentas del predio S'Estorell, y demás predios de la hacienda, muestran jerarquías salariales por cualificación y género eran semejantes a las observadas en otras regiones y periodos: los hombres retenían los trabajos más cualificados (poda, injerto, plantación) y mejor remunerados, mientras las mujeres eran contratadas para las tareas intensivas y reiterativas con inferiores salarios (Garrabou, Pujol \& Colomé, 1991: 32-33; Burnette, 1999; Verdon, 2002; Lana, 1995: 142-143; 2000: 133-134, 144, 147; Fernández Romero, 2005: 48-55; López Estudillo, 2006; Llopis \& García Montero, 2011: 305, 307; Garrabou, Ramon-Muñoz \& Tello, 2015: 98). Sin embargo, puede que la intensa demanda de trabajo y una mayor cualificación de algunas labores masculinas del sector oleícola exportador (Martínez Soto, 2002: 250-266) ejercieran una pulsión al alza sobre el conjunto de la estructura salarial del sector que provocara un premio de la especialización (Williamson, 2012): los salarios femeninos y masculinos de los predios olivareros para labores semejantes eran netamente superiores a los de los predios cerealistas. Sin embargo, ni el premio de la especialización, ni la mayor demanda de trabajo femenino contribuyeron a reducir la brecha salarial de género, que se situaba por debajo del $40 \%$, en una posición igual o inferior que en otras regiones (Fernández Romero, 2005: 61-72; Lana, 2007; García Montero, 2018: 128-131), y muy superior a la que se ha estimado para algunas tareas urbanas para la misma época (Drelichman \& González Agudo, 2019). Por tanto, la mayor ocupación y movilidad de la mano de obra femenina no supuso una mejora relativa de la remuneración femenina respecto de la masculina para la misma labor. 


\section{CONCLUSIONES.}

Las cuentas del predio S'Estorell para mediados del siglo XVII permiten una aproximación al funcionamiento del mercado de trabajo en el sector olivarero de la isla de Mallorca del siglo XVII. La especialización oleícola de exportación se había desarrollado sobre una extremada desigualdad en la distribución de la tierra y la falta de alternativas al trabajo agrícola. En ese contexto los terratenientes se beneficiaron de una escasa regulación de los mercados, que permitió una creciente flexibilidad en cuanto a la segmentación de las labores por géneros y a la movilidad de la fuerza de trabajo. No hay duda de que ello posibilitó la comercialización de aceites grasos a precios competitivos, conteniendo los costes de producción de las haciendas, particularmente los salariales mediante la masiva incorporación de mujeres y niños.

Si bien el sector incentivaba la contratación femenina y proporcionaba salarios más elevados que en otros sectores, no hemos observado que esto contribuyese a cerrar la brecha salarial o mejorar la capacidad de elección de las mujeres. De hecho, la intensa feminización del mercado de trabajo en la isla, bajo las relaciones capitalistas y patriarcales, pudo propiciar un sesgo de género en las relaciones de clase por lo cual el proceso de salarización sería más intenso en las mujeres que en los hombres (Garikipati, 2008).

Por último, las desigualdades económicas en el acceso a la tierra y a otras actividades (factor expulsión), y el diferencial de salarios entre las villas olivareras y cerealistas (factor atracción) pueden explicar, parcialmente, las migraciones estacionales, pero están lejos de ser las únicas explicaciones para esta movilidad. Además de estos factores, las familias tenían que decidir cómo asignaban su fuerza de trabajo (adulto e infantil, masculino y femenino) a los diferentes mercados, pues, como se ha dicho, unas mujeres se quedaban en sus hogares, mientras otras migraban a la sierra.

\section{AGRADECIMIENTOS}

Este estudio se ha beneficiado de la ayuda del Ministerio de Ciencia, Innovación y Universidades PGC2018-096350-B-100. La redacción y revisión de este trabajo se benefició de una estancia en febrero-marzo de 2019 en el Departament of History de la University of Durham. Agradecemos a Julie Marfany y al resto de los miembros del departamento las facilidades que nos depararon. Asímismo una versión revisada del texto se presentó en los seminarios del 15 y 22 de mayo de 2019 en l'École des hautes études en sciences sociales. Agradecemos la invitación de Gérard Béaur y Natalia Muchnick, así 
como los comentarios que hicieron Laurent Hernan, Pablo Luna, Rosa Congost, Ane Zink y Samuel Garrido. También nos gustaría reconocer la asistencia técnica de Juan Galeano y Miquel Valls en la confección del aparato cartográfico del artículo. Por último, agradecemos a los editores y evaluadores anónimos de Historia Agraria, quienes con sus comentarios han contribuido a mejorar este artículo.

\section{REFERENCIAS}

AlberTí, A. \& Morey, A. (1986). El funcionament d'una possessió mallorquina en el primer terç del segle XIx: Son Vivot del Puig d'Inca. Randa, (20), 5-45.

ALLEN, R. C. (2004). Revolución en los campos: La reinterpretación de la revolución agrícola inglesa. Zaragoza: Universidad de Salamanca/Prensas Universitarias de Zaragoza.

Bardhan, P. K. (1984). Land, Labor, and Rural Poverty: Essays in Development Economics. New York: Columbia University Press.

Bavel, B. van (2010). Manors and Markets. Oxford: Oxford University Press.

Bibiloni, A. (1995). El comerç exterior de Mallorca: Homes, mercats $i$ productes d'intercanvi (1650-1720). Palma de Mallorca: El Tall.

Bisson, J. (1977). La terre et l'homme aux îles Baléares. Aix-en-Provence: Édisud.

Borderías, C. \& GÁlvez MuÑoz, L. (2014). Cambios y continuidades en las desigualdades de género: Notas para una agenda de investigación. AREAS: Revista Internacional de Ciencias Sociales, (33), 7-15.

Borderías, C., PÉrez-Fuentes, P. \& SARAsúa, C. (2014). La desigualdad en el consumo familiar: Diferencias de género en la España contemporánea (1850-1930). AREAS: Revista Internacional de Ciencias Sociales, (33), 105-120.

Borrero, M. (2003). Mundo rural y vida campesina en la Andalucía medieval. Granada: Universidad de Granada.

Burnette, J. (1999). Labourers at the Oakes: Changes in the Demand for Female DayLaborers at a Farm Near Sheffield during the Agricultural Revolution. The fournal of Economic History, 59 (1), 41-67.

Burnette, J. (2008). Gender, Work and Wages in Industrial Revolution Britain. Cambridge: Cambridge University Press.

BurnetTe, J. (2013). The Seasonality of English Agricultural Employment: Evidence from Farm Accounts, 1740-1850. En R. W. Hoyle (Ed.), The Farmer in England, 16501980. Farnham: Ashgate.

Burnette, J. (2018). Seasonal Patterns of Agricultural Day-Labour at Eight English Farms. En J. HATCHER \& J. Z. STEPHENSON (Eds.), Seven Centuries of Unreal Wages: The Unreliable Data, Sources and Methods that have been used for Measuring Standarts of Living in the Past. Cham: Palgrave Macmillan. 
CABANA, A. (2018). En femenino plural: La perspectiva de género en la historia rural. En D. Soto \& J. M. LANA (Eds.), Del pasado al futuro como problema: La historia agraria contemporánea española en el siglo XXI: En el XXX aniversario de la SEHA (pp. 189-234). Zaragoza: Prensas Universitarias de Zaragoza.

CARMONA, J. \& Simpson, J. (2003). El laberinto de la agricultura española: Instituciones, contratos y organización entre 1850 y 1936. Zaragoza: Prensas Universitarias de Zaragoza.

De Pleijt, A. \& Zanden, J. L. van (2018). Two Worlds of Female Labour: Gender Wage Inequality in Western Europe, 1300-1800. EHESWorking Papers in Economic History, (138).

Dennison, T. \& Ogilvie, S. (2014). Does the European Marriage Pattern explain Economic Growth? The fournal of Economic History, 74 (3), 651-693.

DEYÀ, M. J. (1998). La manufactura de la llana a la Mallorca moderna (segles XVI-XVII). Palma de Mallorca: El Tall.

Drelichman, M. \& GonzÁlez Agudo, D. (2019). The Gender Wage Gap in Early Modern Toledo, 1550-1650. Vancouver School of Economics, Economic Working Papers, (mauricio_drelichman-2019-7). https://scholar.google.es/scholar?hl=es\&as_sdt= $0 \% 2 \mathrm{C} 5 \& \mathrm{q}=$ Drelichman+\%26+Gonz $\% \mathrm{C} 3 \%$ A 1 lez+Agudo $\% 2 \mathrm{C}+2019 \& \mathrm{btnG}=$

EsCARTín, J. M. (2001). El quefer ocult: El mercat de treball de la dona en la Mallorca contemporània (1870-1940). Palma de Mallorca: Documenta Balear.

Fernández Prieto, L. \& Soto, D. (2010). El Atlántico no es el Mediterráneo: El cambio agrario al otro extremo de la península Ibérica: El mismo estado, otros paisajes, ¿los mismos campesinos? En R. GARRABOU, Sombras del progreso: Las huellas de la historia agraria (pp. 231-264). Barcelona: Crítica.

FERNÁndez Romero, C. (2000). Estudio comparativo de los ciclos de contratación y salario del sector agrícola y el sector de la construcción: Navarra, 1791-1800. Vasconia: Cuadernos de Historia-Geografía, (30), 99-118.

FERnÁNDEZ Romero, C. (2005). Gastos, ingresos y ahorro familiar: Navarra, 1561-1820. Pamplona: Eunsa.

García Montero, H. (2018). Historia agraria y niveles de vida: Estado de la cuestión y propuestas de investigación para la España contemporánea. En D. SoTo \& J. M. LANA (Eds.), Del pasado al futuro como problema: La historia agraria contemporánea española en el siglo XXI: En el XXX aniversario de la SEHA (pp.128-131). Zaragoza: Prensas Universitarias de Zaragoza.

Garikipati, S. (2008). Agricultural Wage Work, Seasonal Migration and the Widening Gender Gap: Evidence from a Semi-Arid Region of Andhra Pradesh. The European Fournal of Development Research, 20 (4), 629-648.

Garrabou, R., Pujol, J. \& Colomé, J. (1991). Salaris, ús i explotació de la força de treball agrícola (Catalunya, 1818-1936). Recerques: Història, economía i cultura, (24), 5376. 
Garrabou, R., Ramon-Muñoz, J. M. \& Tello, E. (2015). Organització social del treball, salaris i mercat laboral a Catalunya: El cas d'una explotació agrària de la comarca de la Segarra a la darreria del segle XIx. Recerques: Història, economía i cultura, (70), 83-123.

GARRIDO, L. (2016). La tasa de actividad femenina en el siglo XVIII en dos municipios andaluces: Laujar de Andarax (Almería) y Úbeda (Jaén). Investigaciones de Historia Económica, 12 (3), 144-153.

GARY, K. (2017). Constructing Equality?:Women's Wages for Physical Labor, 1550-1759. Lund Papers in Economic History, (158). https://ideas.repec.org/p/hhs/luekhi/0158.html

GARY, K. (2019). The Distinct Seasonality of Early Modern Casual Labor and the Short Durations of Individual Working Years: Sweden 1500-1800. Lund Papers in Economic History, (189). https://portal.research.lu.se/portal/files/56865207/LUPEH_189 .pdf

GrAU, E. \& Tello, E. (1985). Anàlisi de la producció agrària mallorquina en els seus dos sectors fonamentals: L'oli i els cereals. Randa, (18), 45-91.

HATChER, J. (2018). Unreal Wages: Long-Run Living Standards and the "Golden Age" of the Fifteenth Century. En J. Hatcher \& J. Z. STEPhenson (Eds.), Seven Centuries of Unreal Wages: The Unreliable Data, Sources and Methods that have been used for Measuring Standarts of Living in the Past (pp. 227-266). Cham: Palgrave Macmillan.

HeRnández, R. (2013). Women's Labor Participation Rates in the Kingdom of Castilla in the Eighteenth Century. Feminist Economics, 19 (4), 181-199.

HindLE, S. (2013). Work, Reward and Labour Discipline in Late Seventeenth-Century England. En S. Hindle, A. ShePARD \& J. WALter (Eds.), Remaking English Society: Social Relations and Social Change in Early Modern England.Vol. 14, (pp. 255-280). Woodbridge: Boydell \& Brewer.

Humphries, J. (2009). The Gender Gap in Wages: Productivity or Prejudice or Market Power in Pursuit of Profits. Social Science History, 33 (4), 481-488.

Humphries, J. (2013). The Lure of Aggregates and the Pitfalls of the Patriarchal Perspective: A Critique of the High Wage Economy Interpretation of the British Industrial Revolution. The Economic History Review, 66 (3), 693-714.

Humphries, J. \& SARAsúa, C. (2012). Off the Record: Reconstructing Women's Labor Force Participation in the European Past. Feminist Economics, 18 (4), 39-67.

Humphries, J. \& WeISDORF, J. (2015). The Wages of Women in England, 1260-1850. The fournal of Economic History, 75 (2), 405-447.

Humphries, J. \& Weisdorf, J. (2016). Unreal Wages?: A New Empirical Foundation for the Study of Living Standards and Economic Growth in England, 1260-1860. Centre for Competitive Advantage in the Global Economy, University of Warwick, Economics Working Paper Series, (310). 
INFANTE, J. (2012). Los temporeros del olivar: Una aproximación al estudio de las migraciones estacionales en el sur de España (siglos XVIII-XIX). Revista de Demografía Histórica, 29 (2), 87-117.

INFANTE, J. (2014). ¿Quién levantó los olivos?: Historia de la especialización olivarera en el sur de España (ss. XVIII-XX). Madrid: Ministerio de Agricultura, Alimentación y Medio Ambiente.

Jover, G. (2013a). Escrutar el mercat de treball a través de la lent de les comptabilitats agràries: El treball a jornal segons els llibres de comptes de Son Costa (Mallorca), 1729-1754. En E. Saguer, G. Jover \& H. Benito (Eds.), Comptes de senyor, comptes de pagès: Les comptabilitats en la història rural (pp. 241-262). Girona: Associació d'Història Rural de les Comarques Gironines/Universitat de Girona/Documenta Universitaria.

JovER, G. (2013b). La difusión del trabajo asalariado infantil en la agricultura mallorquina: Una aproximación a partir de los libros de cuentas de los predios oleícolas, 1700-1850. En J. M. BorRÁs (Ed.), El trabajo infantil en España, 1700-1950 (pp. 27-62). Barcelona: Universitat de Barcelona/Icaria.

Jover, G. (2015). Salarios y movilización del trabajo femenino en el olivar: Mallorca, 1650-1720. EN M. T. ORTEGA (Ed.), fornaleras, campesinas y agricultoras: La historia agraria desde una perspectiva de género (pp.43-64.). Zaragoza: Prensas Universitarias de Zaragoza.

Jover, G. \& Pons, J. (2012). Possessions, renda de la terra i treball assalariat: Lilla de Mallorca, 1400-1660. Girona: Documenta Universitària.

Jover, G., MAS, A., Soto, R. \& TELlo, E. (2019). Socioecological Transition in Land and Labour Exploitation in Mallorca: From Slavery to a Low-Wage Workforce, 1229-1576. Sustainability, 11 (1), 1-26.

Jover, G., PujadAs, J. M. \& SuAu, A. M. (2017). ¿Quiénes eran los mozos en las regiones mediterráneas?: Salarios y movilidad de los mozos en el mercado de trabajo de Mallorca, 1654-1680. Mundo agrario: Revista de estudios rurales, 18 (39).

JuAn VidAL, J. (1989). La distribución de los cultivos en la Mallorca del siglo xvi. Bolletí de la Societat Arqueologica Lul-liana: Revista d'estudis històrics, (45), 165-175.

Juncosa, M. D. \& MARTíneZ, C. (1979). Art de conró compost per Montserrat Fontanet del lloc de Llorito, ólim conductor de son Juan Arnau, y de la Porrasa; mayoral de Masanella, de Lloseta y de son Sanct Juan, segons lo estil de Mallorca, 1747. Estudis d'Història Agrària, (3), 165-196.

LANA, J. M. (1995). Trabajo, técnica y mercado en la viticultura Navarra: Los viñedos del Marqués de San Adrián en Monteagudo durante el siglo XIX. Noticiario de Historia Agraria, 5 (10), 131-158.

LANA, J. M. (2000). Técnicas y procesos de trabajo en la agricultura del sur de Navarra entre los siglos XIX y xx. Historia Agraria, (21), 127-156. 
LANA, J. M. (2007). El poder de compra de jornaleros y criados: Salarios reales y mercados de trabajo en la Navarra rural, (1781-1936). Investigaciones de Historia Económica, (7), 37-68.

Llopis, E. \& García Montero, H. (2011). Precios y salarios en Madrid, 1680-1800. Investigaciones de Historia Económica, 7 (2), 295-309.

LoBATO, I. (1999). Cosecha, producción y transporte de aceite en la Sevilla de 1510: Aproximación al análisis del mercado de trabajo sevillano en el siglo XVI. En P.VILAR \& C. Martínez Shaw (Coords.), Historia moderna, historia en construcción (pp. 189206). Vol. 2. Barcelona: Milenio.

López Estudillo, A. J. (2006). Los mercados de trabajo desde una perspectiva histórica: El trabajo asalariado agrario en la Andalucía Bética (la provincia de Córdoba). Revista Española de Estudios Agrosociales y Pesqueros, (211), 63-119.

Manera, C. (2001). Història del creixement econòmic a Mallorca (1700-2000). Palma de Mallorca: Lleonard Muntaner.

MArco, I. (2018). Dialogues between Nature, Class and Gender: Revisiting Socio-Ecological Reproduction from Past Advanced Organic to Industrial Agricultures (Sentmenat, Catalonia, 1860-1999). http:/diposit.ub.edu/dspace/bitstream/2445/122663/1/ IML_PhD-THESIS.pdf

Martínez Soto, A. P. (2002). Salarios, sindicalismo y procesos de negociación en el área vitivinícola del sureste español, 1890-1935. En J. M. MARTíNEZ CARRIÓN (Ed.), El nivel de vida en la España rural, siglos XVIII-XX (pp.184-235). Alicante: Universidad de Alicante.

MAs-Forner, A., Monjo, J. L. \& MAs, J. (2009). Les arrels margalidanes del poble de Xalò. Santa Margalida: Ajuntament de Santa Margalida.

Molina DE Dios, R. (2003). Treball intensiu, treballadors polivalents (Treball, salaris $i$ cost de la vida, Mallorca 1860-1936). Palma de Mallorca: Govern de les Illes Balears.

Montaner, P. DE \& Le Senne, A. (1977). Aproximación al estudio de la formación de la clase noble en Mallorca: El patrimonio de los Formiguera durante el siglo XVII. Treballs de Geografía, (34), 55-85.

Montaner, P. DE \& Le SenNe, A. (1981). Explotació d'una possessió mallorquina durant la primera meitat del segle Xvi: Son Sureda (Marratxí). Recerques: Història, economía i cultura, (11), 107-124.

Montaner, P. DE \& MoreY, A. (1989). Notas para el estudio de la mano mayor mallorquina durante los siglos XVI y XVII. Estudis Baleàrics, (34), 71-89.

Moor, T. DE \& ZANDEN, J. L. van (2010). Girl Power: The European Marriage Pattern (EMP) and Labour Markets in the North Sea Region in the Late Medieval and Early Modern Period. The Economic History Review, 63 (1), 1-33.

Muldrew, C. (2011). Food, Energy and the Creation of Industriousness: Work and Material Culture in Agrarian England, 1550-1780. Cambridge: Cambridge University Press. 
MuÑoz Abeledo, L. (2012). Women in the Rural and Industrial Labor Force in Nineteenth-Century Spain. Feminist Economics, 18 (4), 121-144.

OgILvie, S. C. (2003). A Bitter Living:Women, Markets, and Social Capital in Early Modern Germany. Oxford: Oxford University Press.

Ortega, M. T. (2015). Introducción. En M. T. ORTEGA (Ed.), fornaleras, campesinas y agricultoras: La historia agraria desde una perspectiva de género (pp. 13-25). Zaragoza: Prensas Universitarias de Zaragoza.

Pascual, A. (2009). Casa i estament social a la ruralia Mallorquina: L'exemple de Binissalem als s. XVII-XIX. Binissalem: Ajuntament de Binissalem.

Ploeg, J. D.vAN DER (2016). El campesinado y el arte de la agricultura: Un manifiesto chayanoviano. Barcelona: Icaria.

Puntas, A. F. \& López Martínez, A. L. (2000). El trabajo asalariado en la agricultura de la Baja Andalucía: Siglos XVIII y XIX. Historia Agraria, (21), 99-126.

REY, O. (2015). El trabajo de las mujeres rurales en la España Moderna: Un balance historiográfico, 1994/2013. Revista de Historiografía (RevHisto), (22), 183-210.

SARASÚA, C. (2019). Women's Work and Structural Change: Occupational Structure in Eighteenth Century Spain. The Economic History Review, 72 (2), 481-509.

SARASÚA, C. \& GÁlvez MuÑoz, L. (2003). Mujeres y hombres en los mercados de trabajo: ¿Privilegios o eficiencia? En C. SARAsúa \& L. Gálvez MuÑoz (Coords.), ¿Privilegios o eficiencia?: Mujeres y hombres en los mercados de trabajo (pp. 9-35). Alicante: Universidad de Alicante.

Schmidt, A. \& NederveEn MEERKerk, E. van (2012). Reconsidering the "FirstmaleBreadwinner Economy": Women's Labor Force Participation in the Netherlands, 1600-1900. Feminist Economics, 18 (4), 69-96.

SEgura, A. \& SuAU, J. (1981). Aproximació a l'estudi de la pagesia mallorquina al primer terç del segle XIx. Bolletí de la Societat Arqueològica Lul-liana: Revista d'estudis històrics, (38), 393-437.

SEgURA, A. \& SuAU, J. (1984). Estudi de demografia mallorquina: L'evolució de la población. Randa, (16), 19-62.

SHARPE, P. (1995). Adapting to Capitalism:Working Women in the English Economy, 17001850. London: Macmillan.

Sharp, P. R. \& WeISDORF, J. L. (2008). A Malthusian Model for all Seasons? PSE Working Papers halshs-00586874.

SNELL, K. D. (1987). Annals of the Labouring Poor: Social Change and Agrarian England, 1660-1900. Cambridge: Cambridge University Press.

SUAU, J. (1991). El món rural mallorquí, segles XVIII-XIX. Barcelona: Curial.

Tello, E. (1983). La producció cerealícola a les petites explotacions pageses des Pla de Mallorca (1850-51). Estudis d'Història Agrària, (4), 167-194. 
Tello, E., Jover, G., Murray, I., Fullana, O. \& Soto, R. (2018). From Feudal Colonization to Agrarian Capitalism in Mallorca: Peasant Endurance under the Rise and Fall of Large Estates (1229-1900). Fournal of Agrarian Change, (48), 483-516.

TRIBE, K. (1981). Genealogies of Capitalism. London: MacMillan.

VERDON, N. (2002). RuralWomen Workers in Nineteenth-Century England: Gender,Work and Wages. Woodbridge: Boydell Press.

VICEDO, E. (2002). Estacionalidad y productividad del trabajo en un marco tecnológico tradicional: Cataluña Occidental, 1750-1890. Historia Agraria, (27), 101-131.

Whittle, J. (2017). Servants in Rural Europe. 1400-1900. Woodbridge: Boydell Press.

Whittle, J. \& Hailwood, M. (2018). The Gender Division of Labour in Early Modern England. The Economic History Review. https://onlinelibrary.wiley.com/doi/full/ 10.1111/ehr.12821

Williamson, J. G. (2012). Comercio y pobreza: Cuándo y cómo comenzó el atraso del Tercer Mundo. Barcelona: Crítica.

Yамамото, C. (2004). Two Labour Markets in Nineteenth-Century English Agriculture: The Trentham Home Farm, Staffordshire. Rural History, 15 (1), 89-116.

ZANDEN, J. L. van (2011). The Malthusian Intermezzo: Women's Wages and Human Capital Formation between the Late Middle Ages and the Demographic Transition of the $19^{\text {th }}$ Century. The History of the Family, 16 (4), 331-342. 